\title{
10. ASSISTÊNCIA SOCIAL, ORÇAMENTO ENXUTO E VIOLÊNCIA ABUNDANTE CONTRA CRIANÇAS E ADOLESCENTES ${ }^{*}$
}

Rodrigo Silva Lima

\section{Introdução}

O presente capítulo é uma atualização dos resultados obtidos na tese de doutorado, "Orçamento público dos abrigos municipais no Rio de Janeiro: velhos e novos dilemas", defendida no Programa de Pós-Graduação em Serviço Social da UERJ. O texto conjuga reflexões que vimos realizando no âmbito do Núcleo de Extensão e Pesquisa em Direitos Humanos, Infância, Juventude e Serviço Social (NUDISS/ UFF) e a partir da reinserção no Grupo de Estudos e Pesquisas do Orçamento Público e da Seguridade Social (GOPSS-UERJ). Busca-se salientar, nesse cenário de crise estrutural do capital, a ampliação da arrecadação municipal, a diminuição do orçamento da assistência social e a dimensão coercitiva do Estado na reorientação das ações de proteção social na cidade do Rio de Janeiro.

A partir da intensificação da crise no Brasil, com o processo que culminou no golpe parlamentar-jurídico-midiático que destituiu Dilma Rousseff do poder, em 2016, a política de assistência social, pressionada pelos aparatos do Poder Judiciário e articulada às instituições repressivas do estado e do município tem sido atravessada por uma face coercitiva, incompatível com os fundamentos normativos dos direitos humanos de crianças e adolescentes e a perspectiva protetiva da Seguridade Social constitucional. No contexto recente, com o aumento da pobreza, o conservadorismo, a focalização e o assistencialismo dos governos, aliados à captura do fundo público para os setores rentistas e ao remanejamento do orçamento da assistência social para ações de repressão, além de enfraquecer a política de 
atendimento, preconizada no Estatuto da Criança e do Adolescente, vem comprometendo um conjunto de instituições e de serviços socioassistenciais, delineados na Política Nacional de Assistência Social (PNAS).

A administração pública garantiu, de forma ainda inacabada, uma infraestrutura para realização de grandes eventos internacionais no Rio de Janeiro e ao racionalizar o orçamento da assistência social resgatou, progressivamente, formatos de repressão e controle junto à população em situação de rua. Com a reorientação dos investimentos públicos, os atores da política de assistência social, contraditoriamente, em vez de assegurarem os direitos dos segmentos sociais mais desprotegidos, cumpriram uma função estratégica na institucionalização forçada, na vigilância e repressão permanente, na expropriação de direitos e no higienismo social do espaço urbano.

\section{Gestão da crise na cidade do Rio de Janeiro}

Nos últimos 20 anos, a capital carioca conhecida mundialmente como "cidade maravilhosa" ou "purgatório da beleza e do caos" ${ }^{1}$, tem sido objeto de disputas de classes antagônicas e prejudicada pelas contradições de interesses mercantis e de negócios lucrativos em face do processo de expansão capitalista no mundo.

Parafraseando uma música de Chico Science e Nação Zumbi, "e no meio da esperteza internacional, a cidade até que não está tão mal, e a situação sempre mais ou menos, sempre uns com mais e outros com menos", pode-se dizer que embora as determinações econômicas internacionais, em grandes cidades de países periféricos, sejam bastante relevantes, elas não são as únicas dimensões a serem consideradas na análise sobre o espaço urbano. Essa análise exige, dentre outras, a compreensão crítica do Estado no capitalismo, a apreensão das tendências ideológicas das políticas sociais e a identificação da sociedade civil na mobilização por direitos. (LIMA, 2016).

\footnotetext{
${ }^{1}$ Quem canta a marchinha de carnaval, de autoria de André Filho, ou a música contagiante, de Fernanda Abreu, jamais poderia imaginar que em 2017, pesquisa do Datafolha, ouvindo mais de 800 moradores, estimaria que $72 \%$, ou seja, sete de cada dez moradores mudariam da cidade por causa do medo e da violência (BARBON, ESTARQUE, 2017).
} 
O modo de produção capitalista é a expressão de um sistema hierarquizado e estruturalmente antagônico que tem afetado a vida da humanidade de diferentes formas nos continentes e em países de economia dependente. Numa organização social tensionada por guerras, por uma lógica expansionista cruel, pelas determinações desumanizadoras da compulsão econômica e pelo ímpeto incontrolável de acumulação capitalista, a crise estrutural do capital figura como um dos fenômenos sociais mais complexos, preocupantes e destrutivos do planeta ${ }^{2}$ (MÉSZÁROS, 2000).

Na literatura especializada, a crise evidenciada nesses últimos anos contribui para reforçar uma perspectiva nada otimista nas análises sobre economia, transporte, cultura e os direitos de cidadania, assim como um horizonte pessimista acerca das relações sociais nas áreas residenciais, comerciais, industriais, turísticas e ambientais das cidades,

[...] o grande e constante contingente de pobres, de desempregados, de empregos precários, de moradias em favelas e cortiços, a exacerbação da violência, tudo isso vem alimentando incertezas quanto ao o futuro das grandes cidades brasileiras (RIBEIRO, 2002, p. 86).

As desiguais relações sociais também se dão pelos vestígios do racismo enraizado na formação sociohistorica e por múltiplas expressões da questão social, onde os detentores dos meios de produção controlam o trabalho e se apropriam da riqueza socialmente produzida e os trabalhadores vendem a força de trabalho em troca de um salário ou, em suas estratégias de sobrevivência, se inserem em ocupações informais e desprotegidas para obter alguma forma de rendimento, por meio de atividades precarizadas ou, no caso da população em situação de rua, também pela ajuda e pela mendicância

\footnotetext{
${ }^{2}$ As situações caóticas delineadas tanto pela "face destrutiva" do capital ou pela "destruição criativa da terra" (HARVEY, 2011, p. 151), como pelas determinações do neoliberalismo, com as medidas de ajuste orientadas pelo Fundo Monetário Internacional e Banco Mundial, contrastam com a "face humana" das legislações e políticas em vigor, em especial, aquelas destinadas para crianças, adolescentes e famílias pauperizadas.
} 
e, nesse sentido, as políticas sociais são muito relevantes (SILVA, 2009, p. 173).

As interseções entre os governos municipais do Rio de Janeiro, nas últimas duas décadas ${ }^{3}$, revelam o recrudescimento do conservadorismo e a continuidade de um projeto de cidade que, por um lado, favorece interesses das classes dominantes em detrimento das necessidades da classe trabalhadora e de segmentos pauperizados e, por outro lado, adota práticas violentas para solucionar conflitos e sustentar desigualdades decorrentes da sociabilidade capitalista. Invariavelmente, os governos cariocas, encarregados por operacionalizar um conjunto de medidas de proteção social, como as políticas de saúde, educação, assistência social e ordenamento urbano, diferenciam-se muito pouco de administrações públicas tecnicistas, orientadas pelas recomendações do ideário neoliberal das agências internacionais e pelas determinações hegemônicas do capital (LIMA, 2013; FARAGE, HELFREICH, CARDOSO, 2019).

Nesse período as ações de repressão adotadas para afugentar a população em situação de rua, sob justificativa de manutenção da ordem urbana ou pelo mote de "prender para proteger", constituíram os principais obstáculos para crianças e adolescentes. A tentativa de impedi-las de circularem pelas ruas e espaços de lazer em regiões mais abastadas ${ }^{4}$, revela o cerceamento do direito à cidade e a negação do direito à convivência comunitária. As relações sociais desiguais, subjacentes aos interesses de comerciais e do mercado imobi-

\footnotetext{
${ }^{3}$ Nessas últimas duas décadas três prefeitos administraram a capital carioca: César Epitácio Maia (1945); Eduardo da Costa Paes (1969) e Marcelo Bezerra Crivella (1957). César Maia governou a cidade em duas gestões, 2001-2004 e entre 2005-2008. Iniciou sua vida política no Partido Comunista Brasileiro (PCB) e, na década de 1980, migrou para o Partido Democrático Trabalhista (PDT) e depois para o Partido do Movimento Democrático do Brasil (PMDB), onde realizou sua primeira gestão como Prefeito, entre 1993-1996. Posteriormente ingressou no Partido da Frente Liberal (PFL), passou rapidamente pelo Partido Trabalhista Brasileiro (PTB) e retornou ao PFL que, em 2007, passou a se chamar Democratas (DEM). Eduardo Paes foi eleito e reeleito para as gestões 2009-2012 e 2013-2016. Iniciou sua carreira no Partido Verde (PV). Integrou o PFL, migrou para o Partido da Social Democracia Brasileira (PSDB) e depois, para concorrer à Prefeitura, se filiou ao PMDB, conduzindo duas gestões municipais. Atualmente está no DEM. Marcelo Crivella se elegeu em 2016. Iniciou sua vida no Partido Liberal (PL) e depois se filiou ao Partido Republicano Brasileiro (PRB) - ou Republicanos.

${ }^{4}$ Os passeios aos Shoppings Centers conhecidos como "rolezinhos" e o impedimento de frequentar as praias da Zona Sul do Rio de Janeiro, na Operação Verão, uma ação coercitiva e racista para prevenir arrastões nas praias.
} 
liário, produzem, não somente, ilusões acerca do significado de proteção social e dos direitos constitucionais, como também contribuem para disseminar o medo e intensificar medidas de privatização da esfera pública e dos espaços urbanos como solução para intensificar os mecanismos de punição, criminalização e opressão contra segmentos pobres e negros, reiterando a tônica da higienização social e a disputa de projetos na cidade (PEREIRA, 2018).

De acordo com Brito e Cardoso (2019), na trilha do impeachment fraudulento, a manobra política que culminou na Emenda Constitucional n 95 (EC 95), aprovada em 15 de dezembro de 2016, tem por objetivo instituir um Novo Regime Fiscal. Ao impor o congelamento dos recursos públicos destinados à educação, saúde, saneamento básico, habitação, previdência, assistência social, etc., a EC-95 terminou fixando um teto de gastos que recai, exclusivamente, sobre as despesas primárias e isso significa que nenhum tipo de congelamento incidirá sobre as chamadas despesas financeiras, referentes aos gastos com juros do sistema de endividamento público. Em linhas gerais, por, pelo menos, cinco gestões presidenciais, as despesas governamentais serão limitadas e teremos obstáculos para a expansão e/ou manutenção de políticas públicas em detrimento das reservas para garantia do pagamento dos juros e amortizações perante os credores da dívida pública no Brasil.

Os municípios também serão atingidos com os desdobramentos sociais impostos pelo teto de gastos do governo federal. Só para se ter uma ideia, de acordo com Brito e Cardoso (2019) em meio aos patamares recordistas de desemprego, subemprego, informalidade e precarização das relações trabalhistas, no final de 2017 o Brasil entrou novamente no mapa da fome e, aproximadamente, onze miIhões de pessoas foram empurradas à condição de extrema-pobreza e insegurança alimentar.

Diante de arrecadações bilionárias, o orçamento destinado para a política de assistência social tem figurado como um recurso público incapaz de retirá-la de uma vergonhosa condição no conjunto da seguridade social constitucional, ou seja, para se atingir patamares dignos de vida isso não se alcança pela lógica do senso comum, "de se fazer muito com pouco ou de substituir o investimento público 
pelo investimento privado, como defendem as teorias econômicas clássicas" (MARIANO, 2017, p. 268)

Mesmo com arrecadações crescentes, a redução do orçamento da assistência social na cidade do Rio de Janeiro é outro vetor que acirra o momento de crise para os segmentos pauperizados em situação de rua. De acordo com a análise da LOA, a receita total estimada nos Orçamentos Fiscal e da Seguridade Social para os anos de 20192020 ultrapassou os trinta bilhões de Reais. Para o ano de 2020, a estimativa de despesa da política de assistência social foi inferior a $2 \%$ da Receita total, algo em torno de quatrocentos e dez mil Reais, o menor percentual observado nas últimas duas décadas (RIO DE JANEIRO, 2019a, 2020a). A assistência social é fundamental, tanto do ponto dos direitos humanos, ao canalizar as suas ações para efetivar a proteção de crianças, adolescentes, deficientes e idosos (BRASIL, 1993), como do ponto de vista econômico, ao enfrentar a pobreza com as políticas de transferência de renda ${ }^{5}$.

Contudo, os avanços recentes na previsão de proteção à infância, na preservação dos laços familiares e na prevenção de violências e violações aos direitos, são insuficientes por reiterar formatos renovados de clientelismo, por explicitar dimensões coercitivas da ação estatal e conservar mecanismos de regulação do mercado de trabalho, ou seja, por sua "histórica função e potencialidade de manter a coesão, a integração e o controle social sobre os pobres" (BOSCHETTI, 2012, p. 53).

Os estados e, principalmente, os municípios, diante da descentralização político-administrativa, têm o papel estratégico na formulação e execução de políticas sociais e seus mecanismos de arrecadação agregam diferentes receitas e, muitas vezes, são complementados pelos recursos federais, por meio do cofinanciamento.

A cidade do Rio de Janeiro, com a realização de grandes eventos internacionais ${ }^{6}$, despontou em investimentos em obras e aumento da arrecadação, porém isso não se traduziu num aumento subs-

\footnotetext{
${ }^{5}$ Há uma estimativa de que a cada $\mathrm{R} \$ 1,00$ transferido pelo governo por meio de gasto social (recursos financeiros destinados aos benefícios previdenciários e programas de transferência de renda) existe um aumento na renda das famílias no valor de $R \$ 1,86$. A cada $R \$ 1,00$, dis ponibilizado pelo governo em políticas de transferência de renda, $\mathrm{R} \$ 0,56$ retorna ao Estado por meio de impostos e arrecadações (VILLAVERDE, 2010).
} 
tantivo dos orçamentos das políticas sociais, em particular, da política de assistência social.

Embora os resultados sociais de um governo não se expressem apenas pela previsão do orçamento, que necessariamente precisa ser, antes de tudo, dilatado, democratizado e transparente, o projeto político dos prefeitos do Rio de Janeiro nas duas últimas décadas tem conjugado uma lógica de "desenvolvimento às avessas" (GONÇALVES, 2012), na qual o chefe do Poder Executivo atua como "mecenas de uma cidade-mercado", num amplo leque de alianças que vai do governo federal ao estadual, passando pelos governos das regiões metropolitanas, rede de televisão, banqueiros, empreiteiros, especuladores financeiros.

\section{Orçamento enxuto da assistência social no Rio de Janeiro}

As políticas sociais de saúde, previdência e assistência social, institucionalizadas no sistema de Seguridade Social previsto na Constituição Federal de 1988, contribuem de forma contraditória para a proteção social ao garantir o assalariamento, para manutenção e reprodução da força de trabalho e, ao mesmo tempo, a reprodução ampliada do próprio capital (MOTA, 1996, p. 191). E o orçamento público das políticas de seguridade social brasileiras, alvo preferencial da "contrarreforma neoliberal" (BEHRING, 2003), tem sido utilizado de maneira difusa, remanejado para outras finalidades ou drenado para o atendimento das exigências de superávit primário e pagamento de juros e amortizações da dívida. As estratégias de luta em defesa das políticas sociais passam pelo no conhecimento, socialização e acompanhamento do orçamento público.

Embora não seja objetivo desse texto esmiuçar as especificidades constitucionais sobre o orçamento para crianças e adolescentes, é importante mencionar o processo que envolve ciclo orçamentário, ou seja, as atividades relacionadas à elaboração e planejamento, à discussão e aprovação, à execução e à avaliação e controle pres-

\footnotetext{
${ }^{6}$ Os Jogos Pan-americanos (em 2007), a Rio + 20 (realizada em 2012), a Copa das Confederações (junho de 2013); a Jornada Mundial da Juventude (julho de 2013) e o Rock in Rio (bianual entre 2011 e 2019), a Copa do Mundo (2014) e as Olimpíadas e Paraolimpíadas (2016).
} 
supõe entender suas complexas relações (SADECK FILHO, 2009). Na arquitetura do orçamento público, a vigência do Plano Plurianual (PPA) é de quatro anos (2014-2017). As diretrizes, os objetivos e as metas são estabelecidos a cada quatro anos e isso permite a continuidade de determinados programas e a politização das prioridades governamentais. Para fins comparativos, no que se refere a arrecadação e despesas da Prefeitura da cidade do Rio de Janeiro, serão colocados em destaque os anos de 2006, 2010, 2014 e 2018 por uma perspectiva metodológica ${ }^{7}$ que favoreça uma leitura mais próxima do papel político do orçamento.

Tabela 1 - Receita arrecadada e despesa paga pela Prefeitura do Rio de Janeiro

\begin{tabular}{|c|c|c|c|c|}
\hline $\begin{array}{c}\text { Prestação } \\
\text { de contas }\end{array}$ & $\mathbf{2 0 0 6}$ & $\mathbf{2 0 1 0}$ & $\mathbf{2 0 1 4}$ & 2018 \\
\hline $\begin{array}{c}\text { Receita } \\
\text { arrecadada }\end{array}$ & $8.703 .728 .000,00$ & $15.243 .212 .000,00$ & $23.972 .480 .000,00$ & $27.673 .484 .000,00$ \\
\hline $\begin{array}{c}\text { Despesa } \\
\text { paga }\end{array}$ & $8.332 .069 .000,00$ & $14.278 .900 .000,00$ & $24.531 .736000,00$ & $27.842 .364 .000,00$ \\
\hline $\begin{array}{c}\text { Déficit ou } \\
\text { Superávit }\end{array}$ & $(+) 371.695 .000,00$ & $(+) 964.312 .000,00$ & $(-) 559.256 .000,00$ & $(-) 168.880 .000,00$ \\
\hline
\end{tabular}

Fonte: Prestação de contas (CGM, 2006, 2010, 2014, 2018). Elaboração própria

Nos outros dois últimos períodos investigados, 2014 e 2018, nas gestões de Eduardo Paes (II) e Marcelo Crivella, foram registradas arrecadações que superaram 23 bilhões e 27 bilhões de Reais, respectivamente, e déficits crescentes de $\mathrm{R} \$ 559.256 .000,00$ e $\mathrm{R} \$$ 168.880.000,00. Cabe ressaltar que, de acordo com o relatório da Controladoria Geral do Município (CGM, 2002, p. 7), "não é objetivo de o poder público municipal apresentar superávits ao longo dos

\footnotetext{
${ }^{7}$ Nessa metodologia de análise, de acordo com Lima (2013), deve-se atentar para o fato de que o primeiro e o último ano do orçamento de cada governo foram descartados em função de não representarem uma projeção mais próxima da realidade e da concepção do gestor no ciclo orçamentário. Por esse motivo, na apresentação dos dados, o primeiro ano da gestão dos prefeitos foi suprimido, pois na verdade o orçamento do exercício $(2005,2009,2013$ e 2016) revela o planejamento anual da gestão anterior e o último ano da gestão (os exercícios de 2008, 2012, 2016 e 2020) também foi descartado, pois diz respeito ao ano eleitoral, momento cujo orçamento tende a ser mais elástico na utilização de benfeitorias, obras etc.
} 
exercícios". Logo, a relação entre a Prefeitura e a população, em princípio, enfatiza que os recursos arrecadados na sociedade deverão retornar para a mesma. Assim sendo, os déficits apurados, geralmente, encontram-se amparados por superávits de anos anteriores.

As receitas que financiam os entes federativos são diferentes, mas estão interligadas, não apenas pela lógica do cofinanciamento, mas pelas exigências da Lei de Responsabilidade Fiscal (LRF) e pela Desvinculação de Receitas da União (DRU) que, a partir de 2015, passou a desvincular até $30 \%$ dos impostos e contribuições. A LRF é um dos mecanismos de ajuste criados no bojo da contrarreforma do Estado para a geração de superávits primários, isto é, para "realização de poupança primária no orçamento para honrar o pagamento dos juros da dívida" (SALVADOR, 2010, p. 380).

Tabela 2 - Despesas com juros e amortizações da dívida e com assistência social

\begin{tabular}{|c|c|c|c|c|}
\hline Prestação de contas & $\mathbf{2 0 0 6}$ & $\mathbf{2 0 1 0}$ & $\mathbf{2 0 1 4}$ & $\mathbf{2 0 1 8}$ \\
\hline & & & & \\
Despesa paga & $\mathrm{R} \$ 8.332 .069$. & $\mathrm{R} \$ 14.278 .900$. & $\mathrm{R} \$ 24.531 .736$ & $\mathrm{R} \$ 27.842 .364$. \\
\hline Juros, encargos e & 812.619 & 1.958 .293 & 1.020 .182 & 1.535 .666 \\
amortizações da & $(9,75 \%)$ & $(13,71 \%)$ & $(4,15 \%)$ & $(5,51 \%)$ \\
dívida & & & & \\
\hline Assistência Social & 279.976 & 339.050 & 791.389 & 610.168 \\
& $(3,36 \%)$ & $(2,37 \%)$ & $(3,22 \%)$ & $(2,19 \%)$ \\
\hline
\end{tabular}

Fonte: Prestação de contas (CGM, 2006, 2010, 2014, 2018). Elaboração própria

A Resolução Conselho Municipal de Assistência Social (CMAS) n. $82 / 2019$, que publica as deliberações da 12a Conferência Municipal de Assistência Social do Rio de Janeiro, tem seguinte texto sobre financiamento público: "assegurar orçamento para a Política de Assistência Social, designando o percentual de 3\% a 10\%". Nessa Conferência, a deliberação propõe um patamar mínimo de $3 \%$, valor bem abaixo dos percentuais deliberados na história das Conferências após a promulgação da Política Nacional de Assistência Social. Desde a V Conferência Nacional de Assistência Social, realizada em Brasília no ano de 2005, há uma deliberação que prevê alteração e aumento progressivo do financiamento da assistência social para Municípios, Estados, União e Distrito Federal. Verifica-se, que na cidade do Rio de 
Janeiro, ao longo dessas últimas duas décadas, os valores destinados à política de assistência social ainda não atingiram sequer a previsão de patamar mínimo, de $5 \%$ do orçamento geral.

Fixar percentual de destinação orçamentária, mediante PEC, para assegurar cofinanciamento e co-responsabilidade da assistência social com destinação orçamentária nas três esferas governamentais, sendo na União vinculado ao orçamento da seguridade social e nas demais esferas de governo ao orçamento geral garantindo, no mínimo, a curto prazo $5 \%$ e, gradativamente, a médio prazo $7 \%$ e a longo prazo $10 \%$, alocados nos respectivos Fundos de Assistência Social, atendendo programas, projetos, serviços e benefícios eventuais estabelecidos pela Política Nacional de Assistência Social, sob pena de responsabilidade fiscal (CNAS, 2005).

De acordo com a Controladoria Geral do Município (2010), a dívida pública é uma das despesas e consiste no pagamento de financiamentos e empréstimos. Observa-se que na prestação de contas do município do Rio de Janeiro (CGM, 2006, 2010, 2014, 2018), as despesas correntes descontam os juros e encargos da dívida e nas despesas de capital são abatidas as amortizações da dívida. No montante de todas as despesas da Prefeitura do Rio de Janeiro, os juros e encargos da dívida e as amortizações da dívida superam todas as despesas com a assistência social.

Em 2014, segundo ano da gestão de Eduardo Paes (II) houve uma redução quando comparado ao exercício de 2010, onde os juros e encargos das dívidas registraram $R \$ 641.589$ milhões e as amortizações da dívida $\mathrm{R} \$ 378.593$ milhões, totalizando $\mathrm{R} \$ 1.020 .182$ bilhões de Reais. No último exercício investigado, que retrata o segundo ano da gestão de Marcelo Crivella, os juros e encargos da dívida saltaram para $\mathrm{R} \$ 823.679$ milhões e as despesas com amortizações da dívida chegaram a $\mathrm{R} \$ \mathbf{1 1} .987$ milhões, totalizando $\mathrm{R} \$ 1.535 .666$ bilhões de Reais, o equivalente a 2,5 vezes a despesa com assistência social para o ano de 2018. 


\section{A face coercitiva da assistência e a violência contra crian- ças e adolescentes}

A prescrição legal da política de assistência social, de acordo com a Lei Orgânica da Assistência Social (LOAS), objetiva garantir a vida; proteger a família, a infância, a adolescência e promover a integração ao mercado de trabalho, dentre outras questões (BRASIL, 1993). Aliás, a intenção de superação do viés assistencialista, clientelista e repressivo das experiências governamentais no Rio de Janeiro sempre esbarrou em contradições intrínsecas ao capital e ao passado escravocrata, tão enraizado na formação sociohistorica brasileira e que opera numa dinâmica conservadora e violenta.

Alvos preferenciais da eliminação física, do aprisionamento, da exploração força de trabalho e da expropriação dos direitos, a população usuária da política de assistência, independente do compromisso ético dos profissionais, tem sido tratada com menosprezo, desrespeito e indiferença.

Em experiências capitalistas de países periféricos e de economia dependente (FERNANDES, 1986), as contradições sociais evidenciadas de forma proeminente e os contrastes políticos, econômicos, sociais e culturais, no processo de formação e desenvolvimento brasileiro revelam, além da exploração da classe trabalhadora e da superexploração da força de trabalho, formas de opressão de negros, muIheres, crianças, adolescentes, jovens e idosos.

Nos estudos de Soares (2016), os fenômenos sociais mencionados se acirram, principalmente, com a realização dos grandes eventos no Brasil, entre 2012 e 2016, onde se verificou um modelo de acumulação que exacerbou as injustiças existentes em períodos pré-capitalistas, como o trabalho escravo, e reproduziram relações sociais profundamente desiguais, como a degradação das condições de vida de amplos contingentes populacionais. Observa-se a expulsão de famílias de suas moradias, o aumento da população em situação de rua, a criminalização da pobreza e dos movimentos sociais, a persuasão de um número recorde de voluntários mesmo diante do desemprego e a manutenção dos privilégios das classes dominantes 
Esse cenário, justificado por avassaladora e ininterrupta sequência de expropriação, por meio da dominância financeira e do rentismo, imputa à hegemonia ${ }^{8}$ do capital mundializado, uma capilaridade ideológica junto aos segmentos da classe trabalhadora e a manutenção de reiterados formatos de violência na sociedade e, nesse sentido, a ideia central a ser salientada se sustenta na seguinte questão: "o caráter histórico das expropriações [...] não seriam apenas um elemento de uma fase passada, inicial e excepcional, mas teriam um papel orgânico na dinâmica histórica do capitalismo" (MAURIEL, 2019, p. 234).

Num contexto de ajuste estrutural, muitas crianças e adolescentes saem de casa impelidas por diversos motivos, como a pobreza, a violência doméstica e intrafamiliar e a intolerância. E aquelas que para "arrumar seu sustento", sob o risco de morte, tinham os corpos e mão de obra explorada em atividades de cunho sexual e no comércio de drogas ilegais, abandonavam, eram rejeitadas ou sequer ingressavam nas escolas. Em algumas circunstâncias a rua, em sua dinâmica contraditória, "acolhia" as necessidade mais imediatas de alimentação e acesso à renda e então, como pedintes, nos malabarismos dos sinais de trânsito, comercializado produtos ou cometendo pequenos delitos, crianças e adolescentes estabeleciam suas estratégias de sobrevivência.

No início do século, em 2002, o Centro Municipal de Atendimento Social Integrado (CEMASI) Casa da Vila, tinha capacidade para atender 20 meninos entre 12 e 18 anos de idade. O perfil desses adolescentes, para além do fato de serem atendidos numa modalidade de abrigo da Prefeitura do Rio de Janeiro, era marcada pelo racismo e expressava a singularidade de experiências de violência, de famílias mergulhadas em severas privações materiais e de violação dos direitos:

\footnotetext{
${ }^{8}$ Baseada na produção de Antônio Gramsci, essa referência se apoia na ideia de que a hegemonia revela um processo de controle, por meio da direção intelectual e moral sobre deter minados grupos: "compreende as tentativas bem-sucedidas da classe dominante em usar a sua liderança política, moral e intelectual para impor sua visão de mundo como inteiramente abrangente e universal, para moldar os interesses e as necessidades dos grupos subordinados" (CARNOY, 1988, p. 95).
} 
1) educação - verificou-se a defasagem entre escolaridade e faixa etária em pelo menos $80 \%$ dos meninos, além de poucos anos de frequência no ensino formal; 2) saúde e alimentação $70 \%$ descreveram saber o que é ter fome, bem como ter utilizado alguma vez álcool e outras drogas; 3 ) respeito e dignidade $-100 \%$ dos adolescentes reclamaram do silenciamento de suas opiniões e desejos; sinalizaram situações de violência intrafamiliar, policial e institucional, vivências traumáticas devido ao abuso e à exploração sexual e por presenciarem a execução sumária de pessoas do seu círculo familiar ou afetivo; 4) proteção e profissionalização - a totalidade apresentou experiência de trabalho infantil e $40 \%$ realizaram alguma atividade considerada ilícita para contribuir com o sustento da família; 5) vida dois meninos (10\%) ostentavam as agruras das ameaças de morte em seus bairros de moradia o que tornava a tarefa de proteção ainda mais ousada; 6) convivência familiar e comunitária - cerca de $30 \%$ dos adolescentes do abrigo relataram a expulsão de casa em virtude da intolerância religiosa, diante do reconhecimento da orientação sexual, ou sofreu o "êxodo da favela", migrando para ruas, em face da sociabilidade violenta evidenciada nos conflitos comerciais entre facções do tráfico (LIMA, 2004a).

Pelo menos três ilustrações acerca das ações protetivas e repressivas do Estado, que evidenciam a dimensão da coerção e do consenso entre os aparatos de segurança pública e a política de assistência social, podem ser destacadas. Nelas, as expressões da questão social que atravessam a vida de crianças e adolescentes demonstram, ao mesmo tempo, o peso do conservadorismo no tratamento dispensado pela prefeitura em relação à população e o rebatimento da ideologia neoliberal na condução da política de assistência social.

Uma primeira questão diz respeito ao processo de criminalização à população que vive em situação de rua. A Guarda Municipal $(\mathrm{GM}-\mathrm{Rio})^{9}$ que em diversificadas ações tem por atribuição proteger o

\footnotetext{
${ }^{9}$ Vinculada à Secretaria Municipal de Ordem Pública (SEOP), foi criada, em 1993, para proteger o cidadão e atuar nas mais variadas frentes: no ordenamento urbano, na fiscalização do trânsito e das posturas municipais, na preservação de bens, serviços e instalações e no apoio às ações de Segurança Pública. Com a experiência da Ronda Escolar, uma menção positiva foi dada à Guarda Municipal por exercer um importante papel de articulação com a educação
} 
patrimônio público; a partir de 2002, passou a recolher sistematicamente, em parceria com a Companhia de Limpeza Urbana (COMLURB), não só os cobertores das crianças e adolescentes que dormiam nas calçadas e debaixo das marquises, mas todos os pertences da população que sobrevivia nas ruas e essa operação foi denominada "cata tralha",

No ano de 2002, tivemos notícia do início da chamada operação "Cata-Tralha" [...] que retirava as pessoas das ruas e jogava seus pertences (documentos, roupas, aparelhos, medicamentos etc.) nos caminhões de lixo. No segundo semestre daquele ano, se realizou a instalação da Comissão Parlamentar de Inquérito (CPI) da População de Rua, na Câmara dos Vereadores, devido às várias denúncias de instituições de direitos humanos. Segundo essas instituições, as pessoas que eram vítimas dessas operações, principalmente no Centro da cidade, eram também instadas a ir para longe do Centro, normalmente para a Baixada Fluminense ou para o município vizinho de Niterói (GATTO, 2011, p. 91).

A segunda questão envolve os conflitos da Guarda Municipal com os trabalhadores ambulantes. Em determinado momento a GMRio, para obter apoio da sociedade e atenuar o descontentamento de parcela dos agentes com as injustiças promovidas, emplacou uma prática institucional "Robin Hood às avessas". Das mercadorias apreendidas na repressão aos camelôs, os gêneros alimentícios eram destinados aos abrigos e creches, porém, chocolates, biscoitos sortidos, refrescos e refrigerantes, produtos presentes na cesta básica das famílias, contraditoriamente, nunca compuseram itens do mapa nutricional das unidades de assistência social. A letra do Rap do TrabaIhador, canção imortalizada documentário “Mc Magalhães, lenda viva do funk", mostra um sucesso nacional, cantado por um trabalhador ambulante, onde se verifica, de maneira divertida e crítica, a face repressiva da Prefeitura do Rio de Janeiro: "Trabalhador ô, vendo bala. Tomaram minha caixa... De Bombom. Do Serenata... De Amor. Que- 
brou a firma... César Maia. Todo mundo duro... Magalhãezê. Roubou meu Chokito... Nananana" (GULARTE, 2013).

A terceira questão denota a dificuldade da desjudicialização na aplicação das medidas protetivas, mesmo com as atribuições do Conselho Tutelar e de uma rede de atendimento consolidada, ainda que de forma insuficiente. Em 2002 a Prefeitura, por meio da Secretaria Municipal de Desenvolvimento Social (SMDS) e da GM-Rio, junto com o Governo do Estado, por meio da Fundação para Infância e Adolescência (FIA) e da Polícia Militar do Estado do Rio de Janeiro (PMERJ), participou do "Projeto Resgate". Esse Projeto, elaborado no âmbito do Juizado da Infância e da Juventude ${ }^{10}$, objetivava a articulação do poder público para efetuar o "recolhimento sistemático de garotos em situação de rua" e se somava às ações do "Projeto Zona Sul Legal"11 (LIMA, 2004). Além da precarização das condições de trabalho, remuneração profissional abaixo do mercado, salários atrasados e redução progressiva das unidades de abrigos mantidos pela Prefeitura da Cidade do Rio de Janeiro, em parceria com Organizações Não Governamentais (ONGs), a insuficiência de retaguarda para atendimento da população de rua infanto-juvenil terminou ocasionando: “1) a superlotação dos abrigos em funcionamento; 2) a queda da qualidade de atendimento; 3) a alta rotatividade dos profissionais e 4) os seguidos e crescentes números de evasões" (LIMA, 2004, p. 108).

A partir de 2005, a Prefeitura da Cidade do Rio de Janeiro, por meio da Secretaria Municipal de Assistência Social (SMAS), se antecipou e começou a realizar mudanças de caráter político-administrativo para atender os pressupostos da Política Nacional de Assistência Social (PNAS) (BRASIL, 2005). Seja na Proteção Social Básica, por meio

\footnotetext{
${ }^{10}$ Na época o Juiz da 1ạ Vara de Infância e Juventude, Siro Darlan de Oliveira, estava afastado e o referido projeto foi elaborado e executado pelo seu substituto. Depois de sua promoção a Desembargador, no ano de 2004, não se viu autoridade judiciária, mais comprometida com a defesa dos interesses de crianças e adolescentes.

${ }^{11}$ Crianças e adolescentes que viviam nas ruas da zona sul, eventualmente, se refugiavam em lugares totalmente inadequados. Não se tratava das calçadas, das marquises ou dos bancos das praças, mas dos bueiros. Um drama naturalizado socialmente inquieta: "aqui [ no bueiro] é quente nos dias de frio. Os guardas municipais não tomam nossos cobertores, os mendigos não jogam garrafa na gente, nem os adultos fazem xixi na nossa cabeça" (DIMENSTEIN, 2005, p. 11, grifos nossos).
} 
da ação dos Centros de Referência de Assistência Social (CRAS), seja na Proteção Social Especial, de média e de alta complexidade, por meio da intervenção de Centros de Referência Especializados de Assistência Social (CREAS), com as equipes de abordagem à população em situação de rua e nos atendimentos em unidades de acolhimento institucional, a assistência social tinha como desafio o enfrentamento da questão social. A institucionalização da PNAS pressupunha em seus objetivos: fortalecer os laços familiares e assegurar a convivência comunitária, dentre outros atendimentos relacionados à violação dos direitos humanos.

Porém, mesmo com os avanços no campo dos direitos humanos e o tardio avanço nas políticas sociais, a lógica perversa, eugênica e fetichista da sociabilidade capitalista, permeada pelo individualismo e por leituras sociológicas epidérmicas, insufla e redireciona o sentimento de medo e de ódio, não mais aos descendentes africanos recém-alforriados ou aos movimentos operários do início do século XX, mas aos seus herdeiros, crianças e adolescentes, em sua maioria, negros e dos segmentos pauperizados da classe trabalhadora (BATISTA, 2003).

E se o discurso acolhedor, que norteou as ações da Secretaria Municipal de Assistência Social ${ }^{12}$, ampliou a visibilidade da política e propiciou maior profissionalismo e compromisso com as prerrogativas do Estatuto da Criança e do Adolescente e da, recém implantada, PNAS, a primeira gestão de Eduardo Paes, retrocedeu na abordagem social. Ao se fazer uma rápida digressão das políticas voltadas para a população infantojuvenil no Brasil, verifica-se que a assistência e a repressão são componentes indissociáveis tanto da face "humanista" da assistência social, vinculada mais recentemente pelas políticas de alívio da pobreza (MAURIEL, 2006), como pela face coercitiva do Estado, com seus mecanismos de cerceamento, controle e criminalização (BRITO; VILLAR; BLANK, 2013; WACQUANT, 2001).

Ao assumir a Secretaria Especial de Ordem Pública do Rio de Janeiro, em janeiro de 2009, Rodrigo Betlhem comandou a Operação

\footnotetext{
${ }^{12}$ Antes Secretaria de Desenvolvimento Social, foi renomeada para Assistência Social para dar visibilidade à política. Voltou a se chamar Desenvolvimento Social nas duas gestões de Eduardo Paes e atualmente, com Crivella, Secretaria Municipal de Assistência Social e Direitos Humanos (SMASDH).
} 
Choque de Ordem e ficou conhecido como "xerife da prefeitura". No bojo das discussões sobre as ações de ordenamento urbano, que ganharam maior visibilidade midiática, uma peculiar e curiosa articulação remanejou Betlhem para a Secretaria Municipal de Desenvolvimento Social, cargo que ocupou de novembro de 2010 a maio de 2012, e que denota, "para além de sua eficiência", a dimensão coercitiva do governo em relação à política assistência social ${ }^{13}$.

Além da presença da Guarda Municipal na organização da movimentação de pedestres, na circulação de automóveis e nas ações direcionadas aos trabalhadores ambulantes ${ }^{14}$, a novidade da Prefeitura do Rio de Janeiro, na última década, se deu no Recolhimento Compulsório de crianças e adolescentes, na repressão ao uso de crack $^{15}$ (MONTOGOMERY et al., 2013) e na Operação e Plano Verão (LIMA, 2016), justamente os anos que antecederam a Copa do Mundo (2014) e as Olimpíadas (2016).

Depois da pressão de inúmeras instituições comprometidas com a consolidação de políticas públicas e direitos humanos, que defendiam a política de redução de danos, os Consultórios na Rua e a ampliação do atendimento em Centros de Atendimento Psicossocial para infância e juventude, dentre outros (OLIVEIRA e DISTLER, 2013), a credibilidade desse Secretário foi abalada não apenas por refuncionalizar o papel da SMDS com aumento da presença coercitiva de sua equipe de abordagem nas ruas, eliminando o que ainda restava de confiança por parte da população usuária, mas fundamentalmente pelas denúncias sobre o desvio de recursos públicos repassados para a ONG Tesloo ${ }^{16}$.

\footnotetext{
${ }^{13}$ Era de conhecimento dos profissionais da abordagem à população em situação de rua a frase "acabou o ECA e agora é a lei do Zeca", um dos braços direitos do Secretário de Desen volvimento Social e que só comprovou a despolitização e o viés coercitivo e conservador da equipe dirigente. (LIMA, 2013, p. 310).

${ }^{14}$ Dados do Comitê Popular da Copa $(2014$, p.61) estimam a existência de até 60 mil trabaIhadores ambulantes na cidade do Rio de Janeiro. [...] Um levantamento feito pelo MUCA no mesmo ano apontava, somente no Centro, a existência de 6 mil vendedores informais chamados do "pulo", caracterizados por exporem suas mercadorias em uma estrutura de fácil desmonte para escapar da fiscalização quando necessário.

${ }^{15}$ Os registros sobre o uso de crack na cidade do Rio de Janeiro ficam mais evidentes a partir do ano de 2005. A dissertação de Silva (2017) faz uma análise crítica acerca dessa expressão da "questão social".
} 
A crise na gestão de Luiz Fernando Pezão, a frente do governo do estado, recaiu sobre a população com anúncio de cortes de serviços, atraso nos pagamentos dos servidores e no aumento dos índices de violência urbana. Esses fatores, segundo pesquisa recente, contribuem para avaliação pessimista dos cariocas em relação ao governo evidenciando, inclusive, a pouca efetividade das Unidades de Polícia Pacificadora (UPPs), criadas em 2008, e da Intervenção das Forças Armadas, em $2018^{17}$. Contudo, a Operação Segurança Presente, criada no final de 2015, vem ganhando fôlego e apoio do poder público.

A proposta financiada pela Fecomércio, em parceria com Prefeitura da Cidade do Rio de Janeiro, em linhas gerais, consiste na contratação de agentes de segurança para atuar coibindo roubos e furtos, o consumo e comércio de drogas e no ordenamento urbano nas áreas patrulhadas. Os agentes fazem também "ações sociais" com o acolhimento de pessoas em situação de rua e desprotegidas. (VIEIRA, 2016; ÍNDIO DO BRASIL, 2018).

Esse tipo de parceria enseja, pelo menos, três indagações críticas. Em primeiro lugar, a focalização de uma Operação dessa envergadura, nas áreas nobres e comerciais da cidade, é uma decisão que tende a manter privilégios e a atender interesses dos empresários. Sendo assim, com os investimentos da Prefeitura esse tipo de ação não fere os princípios republicanos e constitucionais? Em segundo lugar, como os agentes responsáveis pelo patrulhamento são policiais da ativa, da reserva ou jovens que saíram das Forças Armadas, como garantir treinamento de maneira uniforme ou mecanismos de controle, como as corregedorias, para prevenir e julgar as práticas consideradas abusivas? E, por último, não deveria ser esse, mais um mecanismo de repressão social e coação das pessoas nas ruas, que age so-

\footnotetext{
${ }^{16}$ Segundo reportagens, cerca de R\$ 1 milhão foram pagos à ONG Tesloo (em convênio com a Secretaria de Desenvolvimento Social), por serviços não executados O Ministério Público suspeita de desvio de dinheiro e enriquecimento ilícito. Disponível em: <http://g1.globo.com/rio-de-janeiro/noticia/2015/07/mp-ri-investiga-se-socio-de-bethlem-usava-empresaspara-desviar-dinheiro.html>.

${ }^{17}$ De acordo com pesquisa Datafolha, $62 \%$ dos entrevistados apontam que as UPPs não meIhoraram a segurança na cidade. E embora $83 \%$ tenham se mostrado favoráveis a Intervenção das Forças Armadas, 52\% dizem que a ação do Presidente Michel Temer (206-2018) não mudou a realidade local.
} 
bre as consequências sem tocar nas causas dos fenômenos sociais e que contribui para práticas de "limpeza" urbana? (VIEIRA, 2016)

Mesmo com as dificuldades orçamentárias e o discurso que culpabiliza a gestão anterior por um déficit de três bilhões, o Governo Crivella, decidiu pela manutenção dos custos do Programa, em 2018.

Tabela 3 - Comparação da Despesa em Segurança Pública e Assistência Social

\begin{tabular}{|c|c|c|c|c|}
\hline \multirow{2}{*}{$\begin{array}{c}\text { Gestão } \\
\text { Despesas }\end{array}$} & César Maia & $\begin{array}{c}\text { Eduardo Paes } \\
\text { (I) }\end{array}$ & $\begin{array}{c}\text { Eduardo Paes } \\
\text { (II) }\end{array}$ & $\begin{array}{c}\text { Marcelo } \\
\text { Crivella }\end{array}$ \\
\cline { 2 - 5 } & 2006 & 2010 & 2014 & 2018 \\
\hline Despesa Total & 8.332 .069 & 14.278 .900 & 24.531 .736 & 27.842 .364 \\
\hline Segurança & $145.626(1,74 \%)$ & 165.634 & 434.500 & $531.120(1,90 \%)$ \\
Pública & & $(1,15 \%)$ & $(1,77 \%)$ & \\
\hline Assistência & $279.976(3,36 \%)$ & 339.050 & 791.389 & $610.168(2,19 \%)$ \\
Social & & $(2,37 \%)$ & $(3,22 \%)$ & \\
\hline Diferença & 134.350 & 173.416 & 356.889 & 79.048 \\
\hline
\end{tabular}

Fonte: Prestação de contas (CGM, 2006; 2010; 2014; 2018). Elaboração própria

Com a eleição de Jair Bolsonaro (2019-2022), a apresentação de um programa ultraneoliberal alinhado com interesses imperialistas e dos grupos reacionários, as medidas antidemocráticas despontam como principal tendência. A proposta de alteração no Programa Bolsa Família, a criminalização dos movimentos com a redução dos espaços de participação social e o encerramento das atividades de vários Conselhos, mostram que os efeitos do golpe de 2016 exigirão grande capacidade de rearticulação dos segmentos progressistas da sociedade civil. Nesse sentido, os cortes no Programa Habitacional Minha Casa Minha Vida, que desde 2009 vinha reparando desigualdades históricas no cotidiano dos segmentos mais pobres da classe trabalhadora, teve, de acordo com Brito e Cardoso (2019), "a menor dotação orçamentária desde a sua criação, 'com o sacrifício maior recaindo sobre os mais pobres: $R \$$ 4,4 bilhões. Para 2020, a previsão orçamentária é ainda menor: $\mathrm{R} \$ 2,7$ bilhões'”.

Levando em consideração as prestações de contas da Prefeitura nos últimos anos (CGM, 2006-2019), os dados de 2006 e 2007 demonstram que a Prefeitura assegurou para assistência social, res- 
pectivamente, $3,36 \%$ e 3,18\%, do total de despesas da cidade do Rio de Janeiro. De lá pra cá, esse percentual foi sofrendo oscilações. Entre 2010 e 2011 os percentuais caíram para 2,37\% 2,83\% do total de despesas do Poder Executivo, nos anos de 2014 e 2015, se percebe uma pequena elevação do percentual de despesas, 3,33\% e 3,06\%, voltados à política de assistência.

Logicamente, as tendências regressivas do governo federal recaem nos estados e municípios e na gestão de Marcelo Crivella, cujo lema de campanha era "cuidar das pessoas", a tendência de ampliação percentual nos investimentos sociais não prevaleceu e a prestação de contas da assistência social apresentou a mais drástica queda nessas duas últimas décadas. Entre 2018 e $2019^{18}$ os recursos destinados para assistência social passaram a representar, respectivamente, $2,19 \%$ e $2,31 \%$ de todas as despesas municipais, porém, os gastos com segurança pública, embora sejam aparentemente baixos, também oscilaram ao longo das gestões pesquisadas, mas nesse último período as cifras cresceram chegando a, respectivamente, 1,90\% e $1,91 \%$, das despesas municipais, menor diferença percentual quando comparada à assistência social.

Esses dados, isoladamente, podem parecer não explicar muita coisa, mas diante do recrudescimento das ações da prefeitura nas ruas, com as ações sistemáticas de Recolhimento Compulsório, entre 2009 e 2012, período que antecedeu os grandes eventos esportivos internacionais, e na continuidade da Operação Segurança Presente, entre 2016 e 2020, que comprova a tendência dos governos anteriores no estabelecimento de Parcerias Público-Privadas (PPP), percebese a ampliação da dimensão coercitiva do Estado e da precarização das políticas sociais.

Com a defasagem de profissionais, a ausência de concursos públicos e o sucateamento das unidades de atendimento, as cobranças por resultados são intensificadas junto aos profissionais da política de assistência social e a população usuária é duplamente penalizada. $E$ as equipes dos CRAS, dos CREAS, dos abrigos e da abordagem à população em situação de rua que com coragem atendem e medei-

${ }^{18}$ Somente em 2019, a prefeitura do Rio de Janeiro teve uma despesa superior a trinta biIhões de Reais ( $R \$ 30.002 .061 .000,00)$, mas para assistência social foi destinado $R \$ 694.714$ milhões e para segurança pública R\$ 575.121 milhões de Reais (CGM, 2019). 
am situações complexas que exigem grande capacidade de articulação, devem atuar cada vez mais próximas aos movimentos sociais, entidades de atendimento e outras instituições da sociedade civil no processo permanente de mobilização entre trabalhadores e usuários da assistência social.

De um lado, ampliam-se as necessidades não atendidas da maioria da população, pressionando as instituições públicas por uma demanda crescente de serviços sociais. De outro lado, esse quadro choca-se com a restrição de recursos para as políticas sociais governamentais, coerente com os postulados neoliberais para área social, que provocam o desmonte das políticas públicas de caráter universal, ampliando a seletividade típica dos "programas especiais de combate à pobreza" e a mercantilização dos serviços sociais, favorecendo a capitalização do setor privado (IAMAMOTO, 2008, p. 148).

Todos os questionamentos são necessários, porque os governos têm mobilizado suas energias para atuar nas consequências e não preventivamente. O ultraneoliberalismo e a ascensão do conservadorismo acirram múltiplas violências e expressões do racismo, machismo e homofobia que atravessam as vidas de crianças e adolescentes, sejam nas relações domésticas e intrafamiliares, sejam no punitivismo das práticas institucionais e nas ruas da cidade. Por fim, a crise do capital tem um rebatimento nefasto na vida de crianças e adolescentes, sobretudo de segmentos pobres e negros da classe trabalhadora e a equação "orçamento enxuto da assistência social + sobrecarga das famílias + violência abundante" reforça a tese de que o padrão de sociabilidade capitalista atual pressupõe uma "acumulação (democrática) de escombros" (BRITO, 2008).

\section{Considerações finais}

A arrecadação bilionária da cidade do Rio de Janeiro contrasta com o orçamento enxuto da política de assistência social. O conservadorismo dos governos, aliado à violência e à captura do fundo público, além de enfraquecer a política de atendimento a crianças e 
adolescentes, precarizar as condições de trabalho e reduzir, quantitativa e qualitativamente, os servidores concursados, vêm abrindo brechas para a ação de entidades religiosas, como as comunidades terapêuticas, algo que exigirá estratégias de ação dos segmentos que defendem o caráter público da Seguridade Social.

Ao afunilar para área da infância, além das ações higienistas, dos obstáculos para circulação livre nos espaços urbanos, outro fator da violência abundante a ser destacada é a letalidade da ação estatal, principalmente nas favelas. Com a pandemia da COVID 19, são acirradas as dificuldades da assistência social em assegurar plenamente as condições de sobrevivência de determinados segmentos sociais. A tônica tem sido o sucateamento das instituições; a falta de transparência; a situação salarial defasada e pagamentos efetuados com atraso; superlotação de abrigos; alta rotatividade dos membros das equipes de trabalho e a exigência de práticas polivalentes, mesmo diante da insuficiência de processos de formação/capacitação. Evidentemente existiam (e ainda existem) exceções em atendimentos prestados por servidores que lutam para superar a lógica que produz infâncias desiguais.

Diante da crise do capital, as políticas de proteção social são fortemente ameaçadas, não apenas, por procedimentos adotados com maior rigor em gestões de governos neoliberais como a seletividade dos gastos sociais, o contingenciamento dos investimentos e a captura do fundo público, mas pelo caráter focalizado das ações estatais dirigidas a um determinado segmento social. Nesse sentido, a dimensão coercitiva da assistência social, evidenciada quando os interesses das classes dominantes são ameaçados, não se expressa num descompasso momentâneo para afugentar a população em situação de rua (e as crianças e adolescentes), mas revela uma contradição imanente à sua própria existência como política. Se essa reflexão mobilizar a indignação há esperança na luta!

\section{Referências}

BARBON, J. ESTARQUE, M. Violência faz 7 em 10 quererem sair do Rio: pesquisa Datafolha desta semana retrata sensação de medo dos 
cariocas em meio a atual crise de segurança pública. Cotidiano, Folha de São Paulo, 7 de outubro de 2017.

BATISTA, V. M. Difíceis ganhos fáceis: drogas e juventude pobre no Rio de Janeiro (coleção pensamento criminológico). Rio de Janeiro: Revan, 2003.

BEHRING, E. Brasil em contrarreforma: desestruturação do Estado e perda de direitos. São Paulo: Cortez, 2003.

BOSCHETTI, I. América Latina, política Social e pobreza: "novo" modelo de desenvolvimento? In: BEHRING, E., et.al. (Orgs.). Financeirização, fundo público e política social. São Paulo: Cortez, 2012.

BRASIL. Lei 8.069 de 13 de julho de 1990 - Estatuto da Criança e do Adolescente. Disponível em: <http://www.planalto.gov.br/ccivil_03/ leis//8069.htm>. Acesso em: 5 ago. 2020.

. Lei 8.742 de 7 de dezembro de 1993 - Lei Orgânica da Assistência Social. Disponível em: <http://www.planalto.gov.br/ccivil_03/ leis/l8742compilado.htm>. Acesso em: 15 ago 2020.

. Política Nacional de Assistência Social, resolução no. 145, de 15 de outubro de 2004 (Diário Oficial da União, 28/10/2004), 2005.

BRITO, F. Acumulação (democrática) de escombros. 2010. Tese (Doutorado) Pós-graduação em Serviço Social da Universidade Federal do Rio de Janeiro. Rio de Janeiro, 2010.

. ; CARDOSO, R. O. Nas trilhas do golpe: sobre a devastação como tecnologia de governo. Blog da Boitempo, 2019. Disponível em: <https://blogdaboitempo.com.br/2019/11/01/nas-trilhas-do-golpenotas-sobre-a-devastacao-como-tecnologia-de-governo/>. Acesso em: 30 set. 2020 .

;; VILLAR, A.; BLANK, J. Será Guerra? In: BRITO, F.; ROCHA, P. (org.). Até o último homem: visões cariocas da administração armada da vida social. São Paulo: Boitempo, 2013.

CARNOY, M. Estado e teoria política. 2. ed. São Paulo: Papirus, 1988. 
CMAS. Resolução n.9 82/2019. Deliberações da 12a Conferência Municipal de Assistência Social do Rio de Janeiro. Conselho Municipal de Assistência Social. Rio de Janeiro, 2019.

CNAS. Conselho Nacional de Assistência Social. Deliberações da 5a Conferência Nacional de Assistência Social. Estratégias e Metas para Implementação da Política de Assistência Social no Brasil, Brasília, 2005

COELHO, L. R. V. Operação Segurança Presente: uma análise do Programa implementado na cidade do Rio de Janeiro. 2017. Trabalho de Conclusão de Curso. Faculdade de Direito, Rio de Janeiro, UFRJ, 2017 COMITÊ POPULAR DA COPA E OLIMPÍADAS DO RIO DE JANEIRO (CPCORJ). Megaeventos e Violações dos Direitos Humanos no Rio de Janeiro. Dossiê do Comitê Popular da Copa e Olimpíadas do Rio de Janeiro, 2014.

DIMENSTEIN, G. $\mathbf{O}$ cidadão de papel: a infância, a adolescência e os direitos humanos no Brasil. São Paulo: Editora Ática, 2005.

FARAGE, E. HELFREICH, F. CARDOSO, I. Questão urbana, direito à cidade e o Serviço Social. In: RAMOS, A.; et al. (Orgs.) Desenvolvimento, formação social brasileira e políticas públicas: subsídios analíticos para o Serviço Social. Uberlândia: Navegando Publicações, 2019.

FERNANDES, F. Capitalismo dependente e classes sociais na América Latina. Rio de Janeiro: Zahar, 1986

GATTO, M. E. O outro lado de uma política de governo na reprodução e perpetuação de desumanidades: o recolhimento de crianças e adolescentes em situação de rua na cidade do Rio de Janeiro. Dissertação (Mestrado) -Programa de Pós-Graduação em Políticas Públicas e Formação Humana, UERJ: Rio de Janeiro, 2011.

GONÇALVES, R. Novo desenvolvimentismo e liberalismo enraizado. Revista Serviço Social e Sociedade. São Paulo: Cortez, 2012.

GULARTE, M. Mc Magalhães, lenda viva do funk, curta metragem, 15 min., Brasil, 2013. Disponível em: <https://filmow.com/mc-magaIhaes-uma-lenda-viva-do-funk-t85523/>. Acesso em: 30 set. 2020. 
HARVEY, D. O enigma do capital e as crises do capitalismo. São Paulo: Boitempo, 2011.

IAMAMOTO, M. V. Serviço Social em Tempo de Capital Fetiche. 3. ed. São Paulo: Cortez, 2008.

INDIO DO BRASIL, Cristina. Prefeitura do Rio decide manter parceria no Programa Centro Presente. Rio de Janeiro. Agência Brasil, 2018. Disponível em: <https://agenciabrasil.ebc.com.br/geral/noticia/201807/prefeitura-do-rio-decide-manter-parceria-no-programa-centropresente>. Acesso em: 30 set. 2020.

LIMA, R. A relação entre educação e assistência social no Brasil: políticas de atendimento à infância e à adolescência no município do Rio de Janeiro. 2004. Dissertação (Mestrado), FSS/UERJ, Rio de Janeiro, 2004.

Anotações de trabalho. Prefeitura da Cidade do Rio de Janeiro, Cemasi Casa da Vila, 2004a.

. Convivência comunitária para que e para quem? In: FRENTE NACIONAL DOS PREFEITOS (FNP). Projeto Rio 2016: Olimpíadas dos Direitos de Crianças e Adolescentes. Rio de Janeiro: União Europeia (UE); Iscos Piemont; Viva Rio; CEDECA; PCRJ/SMDS; UNICEF, 2016.

. Orçamento Municipal dos Abrigos no Rio de Janeiro: velhos e novos dilemas. 2-13. Tese (Doutorado), PPGSS/UERJ, Rio de Janeiro, 2013.

MARIANO, C. M. Emenda constitucional 95/2016 e o teto dos gastos públicos: Brasil de volta ao estado de exceção econômico e ao capitalismo do desastre. Revista de Investigações Constitucionais, Curitiba, v. 4, n. 1, p. 259-281, jan./abr. 2017.

MAURIEL, A. P. Combate à pobreza na América Latina: impasses teóricos e ideológicos na construção da política social contemporânea. In: Ser Social, n. 18. Programa de Pós-graduação em Política Social da UnB, 2006.

. Estado e expropriações no capitalismo dependente. BOSCHETTI, Ivanete (Org.) Expropriação e Direitos no Capitalismo. São Paulo: Cortez, 2018. 
MÉSZÁROS, I. Crise Estrutural do Capital. Revista Outubro, edição n. 4, ano, 2000. Disponível em: <http://outubrorevista.com.br/a-criseestrutural-do-capital/>. Acesso em: 16 set. 2020.

MONTOGOMERY, A.; et.al. Recolhimento e internação compulsória: uma política violadora de direitos humanos. Rio de Janeiro: CEDECA, 2013.

MOTA, A. E. Seguridade Social. Revista Serviço Social e Social, n. 50. São Paulo: Cortez, 1996.

OLVEIRA, H. C.; DISTLER, S. D. C. Posicionamento do Conselho Regional de Serviço Social do Rio de Janeiro. In: MONTOGOMERY, A.; et.al. Recolhimento e internação compulsória: uma política violadora de direitos humanos. Rio de Janeiro: CEDECA, 2013.

PEREIRA, T. D. Higienismo social e disputa de projetos de cidade. Emancipa: o cotidiano em debate - CRESS 9o Região. n.3, maio. 2018. São Paulo: CRESS 9o Região, 2018.

RIBEIRO, L. C. Q. A cidade, as classes e a política: uma nova questão urbana brasileira? In: OLIVEIRA, L. L. (Org.) Cidade: história e desafios. Rio de Janeiro: Editora FGV, 2002. 296p. Disponível em https://cpdoc.fgv.br/producao_intelectual/arq/1264.pdf Acesso em: 25 set. 2020

RIO DE JANEIRO. Controladoria Geral do Município (CGM). Prestação de Contas Simplificada do exercício de 2006/2007. Disponível em: <http://www.rio.rj.gov.br/web/cgm/publicacao-cgm>. Acesso em: 15 jan. 2013.

. Controladoria Geral do Município (CGM). Prestação de Contas Simplificada do exercício de 2010/2011. Disponível em: <http://www.rio.rj.gov.br/web/cgm/publicacao-cgm>. Acesso em: 15 jan. 2013.

. Controladoria Geral do Município (CGM). Prestação de Contas Simplificada do exercício de 2014/2015. Disponível em: <http://www.rio.rj.gov.br/web/cgm/publicacao-cgm>. Acesso em: 20 dez. 2019. 
. Controladoria Geral do Município (CGM). Prestação de Contas Simplificada do exercício de $\mathbf{2 0 1 8 / 2 0 1 9 / 2 0 2 0 . ~ D i s p o n i ́ v e l ~ e m : ~}$ <http://www.rio.rj.gov.br/web/cgm/publicacao-cgm>. Acesso em: 08 ago. 2019.

. Lei Orçamentária Anual. Rio de Janeiro: Secretaria Municipal de Fazenda, 2019a; 2020a. Disponível em http://www2.rio.rj.gov.br/ smf/orcamento/loa.asp

SADECK FILHO, F. J. Orçamento público e fundo dos direitos da criança e do adolescente. In ASSIS, S. G. et al. (org.). Teoria e prática dos Conselhos Tutelares e Conselhos de Direitos da criança e do adolescente. Rio de Janeiro: Ed. Fiocruz; Educação à distância da Escola Nacional de Saúde Pública Sérgio Arouca, 2009.

SALVADOR, E. Fundo público e seguridade social no Brasil. São Paulo: Cortez, 2010.

SILVA, A. P. C. A política de drogas na "Cidade Maravilhosa": pedras no meio do caminho. Dissertação (Mestrado em Serviço Social) - Programa de Pós-Graduação em Serviço Social e Desenvolvimento Regional, Universidade Federal Fluminense: Niterói, 2017.

SILVA, M. L. L. A população em situação de rua no Brasil no período entre 1995 e 2005: perfil e relação com as políticas sociais (capítulo III). In: Trabalho e população em situação de rua no Brasil. São Paulo: Cortez, 2009.

SOARES, M.. País dos megaeventos e da violação aos direitos trabaIhistas e humanos. In: FIGUEIRA, Ricardo Rezende; PRADO, Adonia Antunes; GALVÃO, Edna Maria. (Org.). Discussões contemporâneas sobre trabalho escravo: teoria e pesquisa. 1a ed. Rio de Janeiro: Mauad X, 2016, v. , p. 211-236.

VIEIRA, I. Operação de segurança no Rio financiada pela Fecomércio divide opiniões. Rio de Janeiro: Agência Brasil, 2016. Disponível em <https://agenciabrasil.ebc.com.br/geral/noticia/2016-06/operacaode-seguranca-no-rio-financiada-pela-fecomercio-divideopinioes\#: :text=A\%200pera\%C3\%A7\%C3\%A30\%20Seguran 
\%C3\%A7a\%20Presente\%20\%C3\%A9,de\%20recursos\%20pr\%C3\%B3prios\%20no\%20programa> Acesso em: 30. Set. 2020

VILLAVERDE, J. Sem reforma tributária, política social fica comprometida, dizem especialistas. Jornal Valor Econômico. São Paulo, 01 de julho de 2010. Disponível em:<http://www.ipea.gov.br/portal/index.php?option=com_content\&view=article\&id= 1480\&catid=159\&Itemid=75>. Acesso em: 19 mar. 2011.

WACQUANT, L. Punir os pobres: a nova gestão da miséria nos Estados Unidos. Rio de Janeiro: Instituto Carioca de Criminologia: F Bastos, 2001.

\section{Sobre o autor}

Rodrigo Silva Lima - Doutor e Mestre em Serviço Social pelo Programa de Pós-Graduação em Serviço Social da Universidade do Estado do Rio de Janeiro. Educador social, assistente social, professor da Graduação e do Programa de Pós-Graduação em Serviço Social e Desenvolvimento Regional da Escola de Serviço Social da Universidade Federal Fluminense. Coordenador do Núcleo de Extensão e Pesquisa em Direitos Humanos, Infância, Juventude e Serviço Social (NUDISS/ UFF) e coordenador do Grupo Temático de Pesquisa: Serviço Social, Gerações e Classes Sociais da ABEPSS (2019-2020).

E-mail: rodrigorrod@hotmail.com 